\title{
JOB AUTONOMY, JOB CRAFTING AND EMPLOYEES' WELL-BEING DURING WORKING FROM HOME
}

\author{
Susanti Saragih ${ }^{*}$, Meily Margaretha ${ }^{2}$, Luthfia Aufanzylla Anantyanda ${ }^{3}$ \\ 1,2,3 Faculty of Business, Maranatha Christian University, Indonesia \\ Email: 1'susanti.saragih@eco.maranatha.edu, ${ }^{2}$ meily.margaretha@eco.maranatha.edu, ${ }^{3}$ aufanzyllaxluthfia@gmail.com \\ *Corresponding author
}

\begin{abstract}
Nowadays, organizations have focused more on employees' well-being because people have to work from home (WFH) or practice hybrid work and adapt to a new routine of work and life since COVID-19 struck the world. During working from home, employees expect more flexibility on how to handle their tasks - this is known as job autonomy. This study aimed to examine the relationship between job autonomy and wellbeing, and the mediating effects of job crafting on job autonomy and employees' well-being during WFH in COVID-19 Pandemic. An online survey was conducted and there were 427 respondents involved. The model was analyzed using WarpPLS 7.0 and the results showed that no significant relationship was found between job autonomy and well-being. However, there was a relationship between job autonomy and job crafting, as well as between job crafting and well-being. Job crafting significantly mediated the relationship between job autonomy and well-being. This study showed that during WFH, employees have experienced an excessive degree of freedom in doing their tasks, and it had given them more pressure and decreased employees' subjective well-being. The findings may be valuable in all kinds of organizational settings when reviewing and proposing job design and well-being policies.
\end{abstract}

Keywords: Job crafting, job autonomy, well-being, job design, COVID-19 pandemic.

\section{Introduction}

The nature of work has been changing at a faster pace than ever before. Technological advancements have entirely reshaped organizations, implemented various flexible work arrangement (FWA), modified the methods work, and reduced the boundaries between work and personal life (Franken et al., 2021). These changes are significant because employees can add value by harnessing technologies to be creative, innovative, and adaptable. Nevertheless, employees need to be at a good level of physical, mental, and emotional conditions to accomplish all tasks and adapt to these vast changes. As a result, there are some indications that nowadays employees pay more attention to their well-being as it affects their quality of life.

This growing attention on well-being has gripped the world of work (Simone, 2014). Many organizations have begun implementing well-being programs within the workplace. These have even become more prioritized since COVID-19 struck the world. This pandemic has created an even more uncertain environment for both employers and employees. Workplace stress reaches an unprecedented level because people have to work from home and adapt to a new routine of work and life. Physical activities such as going to the public area, groceries, out to the gym have been disrupted. Employees experience financial and job insecurity because of layoffs, anger and sadness because of loneliness, and loss of a family member (Vyas \& Butakhieo, 2021). Employees who need to work from the office are more likely to work in fear and stress of the risk of exposure to the virus, and the increased demand for certain tasks and services.

A recent study found that the more time employees spent working remotely (versus working from the office) the higher their expectation of flexibility (International Labour Organization, 2020; Palumbo, 2020; Gajendran, Harrison, \& DelaneyKlinger, 2014). For instance, employees may be able to change the measurement of productivity by focusing on outcomes rather than working hours, and on unspecific work hours, but total weekly hours remain unchanged, or by utilizing different methods to handle their job demand and responsibilities (International Labour Organization, 2020). Working from home (WFH) should enable employees to take appropriate steps to manage their job situation without direct supervision from their supervisor/manager. This temporary alternative work arrangement requires mutual trust between employees and managers (International Labour Organization, 2020), so employees freely make task-related decisions, scheduling work tasks, and select work methods, this known as job autonomy (Hackman \& Oldham, 1976).

Job autonomy and flexibility create an environment where self-initiation, proactivity, and flexibility are promoted (Slemp, Kern, \& Vella-Brodict, 2015). 
Job autonomy increases individual's sense of responsibility for their performance because an employee who has enough independence and freedom to make decision on their daily task will apply their knowledge, preference, and experiences to conduct and perform the job, and even to solve difficult problems at works. Flexibility at work promotes positive results by enhancing employee's engagement, ownership, including recognize the purpose of their job, and willingness to modify the methods of work (Zhou, 2020).

Several studies (Sekiguchi, Li, \& Husumi, 2017; Debus, Gross, \& Kleinmann, 2019; Saragih, Margaretha, \& Situmorang, 2020) have shown that employees who perceived enough control over their work are more likely to have higher satisfaction, performance, and well-being. A satisfactory level of autonomy at workplace permits employees to do a more extensive range of tasks, redefine their roles, and modify job aspects that will reach an effective method of work, and will then become a precondition for work crafting (Kim, Im, Qu, \& Koong, 2018). In reality, an employee becomes "crafter" of their work when the workplace provides flexibility and space for employee to make decision on redesigning their jobs, and balancing workload and resources. Subsequently, this decisionmaking creates a more engaging, meaningful, and enthusiastic working experience (Wrzesniewski \& Dutton, 2001; Slemp et al., 2015; Van-Wingerden, Bakker \& Derks, 2017) because employee will have a lower stress and a higher psychological availability that could in turn enhance employees' well-being (Van-Wingerden et al., 2017).

However, studies on autonomy and positive outcomes during this pandemic revealed a different result. Palumbo (2020) found that autonomy offered in homebased telecommuting work negatively affected employees' work-life balance and triggered higher fatigue during the pandemic. Often, WFH interferes with personal life, blurs the boundaries of work and personal life because of an increase in work hours and an intensification of work. It is speculated that workers' well-being and performance will be affected. In Japan, a research showed that working hours and time off ambiguity were the highest-ranked disadvantage of remote working (Sato, 2019). Vyas and Butakhieo (2021) also discovered that work from home during quarantine leads to an unhealthy lifestyle (lying on the sofa all day or sitting on an unsuitable chair), lowers motivation, and enhances cyberslacking.

The key objectives of this study are to explore the association between job autonomy and well-being, and the mediation effect of job crafting on job autonomy and well-being during working from home in COVID19 Pandemic. This study contributes to the job design literature in exploring the mechanism of job autonomy and its influence on job crafting and well-being. While previous studies have been conducted in various industries and countries on normal situation, this study was conducted during the COVID-19 Pandemic. The reason for doing the study is employees who work remotely have a higher need for autonomy. Moreover, the findings will help the practitioners in facilitating the factors that promote autonomy and well-being during the period of remote working.

\section{Job Autonomy and Well-Being}

A broad theory of human motivation, the self-determination theory, explains that humans have three intrinsic psychological needs: connectedness, autonomy, and competence (Deci \& Ryan, 2008). Autonomy is characterized as the extent to which the job presents valuable freedom, independence, flexibility to make changes, and choice in determining the procedures to execute the work successfully (Deci \& Ryan, 2008). Relatedness represents the individuals' need to experience a sense of affinity and connection with other people. The need for relatedness is satisfied when the worker has a supportive relationship and feels cared for by others. Meanwhile, competence is defined as the human need to feel capable, successful, and able to accomplish their work effectively.

When employees are granted a satisfactory degree of job autonomy, they can execute their tasks by applying their knowledge, skills, and abilities efficiently. This would lead to a positive effect on employees' well-being (Park \& Searcy, 2012; Petrou, Demerouti, \& Schaufeli, 2012; Park \& Jang, 2015; Kim et al., 2018). According to Yang and Zhao (2018) and Petrou et al. (2012), individuals' psychological well-being would increase dramatically when they experience independence and autonomy at the workplace because they would use their creativity, authority, and power to handle their work and have more chances to cope with the stressful work situation. It also promotes job satisfaction, organizational engagement, worker's mental health, and decreases stress level.

Previous studies proposed that job autonomy has become a precondition of proactive workplace behavior, i.e. job crafting (Chang, Rui, \& Wu, 2021; Kim et al., 2018; Li, Han, Qi, \& He, 2020). Job crafting is defined as employee's self-initiative actions in changing the physical and cognitive aspect in the task or relational boundaries of their work (Wrzesniewski \& Dutton, 2001; Tims, Bakker, \& Arnold, 2010). Employees may modify their jobs based on their needs and preferences by changing tasks' scope, number of tasks, skills used at work, or relationships with customers or colleagues (Tims et al., 2010; Wrzesniewski \& Dutton, 2001). 
This implied that some degree of flexibility during work from home enables the employee to modify aspects of their works to align them with their personal needs and preferences (Tims, Bakker, \& Derks, 2012; Van-Wingerden et al., 2017; Wrzesniewski \& Dutton, 2001). Therefore, we hypothesize that: can control and de-

cide on their own methods of work, work arrangements, and work standards

$H_{l}$ : Job autonomy will be positively related to employees' well-being.

$H_{2}$ : Job autonomy will be positively related to job crafting.

\section{Job Crafting and Well-Being}

Job crafting is defined as a mechanism by which employees voluntarily change some aspects of the job (i.e. physical, cognitive, and psychosocial aspects) to increase performance and fit with their skill, knowledge, and career preference (Wrzesniewski \& Dutton, 2001; Tims et al., 2012). The motivation for job crafting roots from employees' basic needs, the need to take control, the need to have a meaningful experience, and the need of connection with others. Employee becomes "crafter" of their daily tasks because they want to take control over the method, scope and the result, able to reduce daily stress at workplace, and create work climate in which they can work happier and more motivated (Chang et al., 2021).

Tims et al. (2012) stated that job crafting consisted of four dimensions: increasing the structural job resources, increasing challenge on the job, decreasing hindering job demands, and increasing social aspects of the job. Increasing structural job resources refers to the assortment of resource and opportunity for personal growth. This response lowers the adverse effects of high job demand and contributes to higher work dedication and job satisfaction (Hakanen \& Roodt, 2010; Tims et al., 2012). Increasing challenging job demands is an opportunity to generate more challenges at work so that employees experience an acceptable degree of challenging job loads and requirements (Demerouti \& Bakker, 2014). Meanwhile, decreasing hindering job demand is defined as a self-initiated change that employees make to lower their job requirements when they perceived that their job loads have become devastating. Decreasing the degree of job demands may reduce the adverse health effects such as burnout and boredom (Tims et al., 2012; Van-Wingerden et al. 2017). Finally, employee crafts their work by changing social aspect of the job (i.e. asking for advice, feedback, and coaching).
Prior research that has applied person-job fit theory (e.g. Kristof-Brown, Zimmerman, \& Johnson, 2005) enlightens that poor employee well-being is a result of misfit between the abilities, needs, and values of the worker. During work from home, employees' daily living routines have been disrupted, which may cause added stress, tension, and physical. Therefore, if an employee has the flexibility to modify their work (i.e. the ability to arrange the number and types of daily tasks, the amount of interaction with others, and how they think about or perceive their jobs), it will lead to a fitness between person and job (Wrzesniewski \& Dutton, 2001; Crawford, LePine, \& Rich, 2010). Crafting work with these three methods would enable an employee to work according to their values and preferences, more engaged at work (Nielsen \& Abildgaard, 2012; Van-Wingerden et al., 2017), be satisfied with their work, perform better (Guan \& Frenkel, 2018), and experience lower levels of stress (Singh \& Singh, 2018). Therefore, we hypothesize:

$H_{3}$ : Job crafting will be positively related to employees' well-being

\section{Job Autonomy, Job Crafting, and Well-being}

It has been stated that job autonomy is a requirement for employees to craft their daily tasks. A high degree of job autonomy will trigger job crafting by signaling employees that they have enough opportunity and independence to take initiative changes (Petrou et al., 2012; Sekiguchi et al., 2017; Debus et al., 2019; Saragih et al., 2020). In addition, studies indicate that a higher level of autonomy encourages employees to execute a range of tasks, responsibilities, and will be positively related to a higher level of self-efficacy and intrinsic motivation (Slemp et al., 2015; Saragih et al., 2020). Not only increase motivation, the Job DemandResource Model (JD-R model) also improves the number of structural resources, social resources, and challenges at a job. These could be improving one's capabilities, asking for coaching or advice, proactively participate in new projects, making the job mentally less intense). Therefore, the employee would also have a sense of energy and engagement with their works and experiencing a sense of significance and satisfaction (Van-Wingerden et al., 2017; Singh \& Singh, 2018). As a consequence, this could enhance the well-being of the employees. Thus, it is hypothesized that job autonomy would increase well-being through job crafting as a mediating variable (Figure 1).

$H_{4}$ : Job autonomy is related to well-being through job crafting as a mediating variable. 


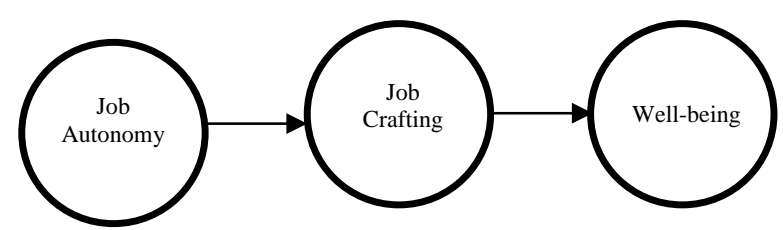

Figure 1. The conceptual research framework

\section{Research Method}

\section{Sample and Procedure}

The sample of this study is employees who have been working for a minimum of one year in Bandung and Jakarta. The minimum sample size was calculated based on the number of parameters. An online survey was conducted by targeting employees who have been working for one year in Bandung or Jakarta and 427 respondents participated in this research (Table 1). Respondents were categorized in gender, age, educational background, and employment status. The majority of respondents were female $(47 \%)$ and the prevailing age was in the age range of $>46$ years old $(19.60 \%)$. Nearly one-third of the respondents have a bachelor's degree $(31.50 \%)$ and works as permanent workers $(54.80 \%)$.

Table 1

Respondents Profile $(n=427)$

\begin{tabular}{lrr}
\hline & Number of Respondents & Percentage \\
\hline Gender & 139 & \\
$\quad$ Male & 288 & 22.70 \\
$\quad$ Female & & 47.00 \\
Age & 84 & \\
23-28 & 88 & 13.70 \\
$29-34$ & 85 & 14.40 \\
$35-40$ & 50 & 13.90 \\
41-46 & 120 & 8.20 \\
$\quad>46$ & & 19.60 \\
Education & 7 & \\
$\quad$ High School & 169 & 1.10 \\
$\quad$ Diploma & 193 & 27.60 \\
$\quad$ Bachelor's degree & 58 & 31.50 \\
$\quad$ Master's degree & & 9.50 \\
Employment Status & 336 & \\
$\quad$ Permanent Worker & 91 & 54.80 \\
$\quad$ Temporary Worker & & 14.80 \\
\hline
\end{tabular}

\section{Measures}

This study followed the instrument developed by Tims et al. (2012). It consists of four dimensions of job crafting (increasing structural job resources, decreasing hindering job demands, increasing social job resources, and increasing challenging job demands). A sample of the item is "I make sure that my work is mentally less intense". There are 21 items on a five-point Likert scale measuring each of the four dimensions.
The scale of job autonomy is adopted the instrument developed by Breaugh (1999) that consists of nine items. A sample item is "I am free to choose the methods to use in carrying out my work".

The survey adopted the workplace well-being (WWB) instrument developed by Warr (1990). It consists of 12 descriptor words (both positive affect and negative affect). Respondents indicate the frequency of each emotion they experience at work for the last two months.

To examine whether the variables (job autonomy, well-being, and job crafting) assessed were distinct from one another, we conducted reliability test using WarpPLS 7.0. Table 2 described the loading factors' results. Indicators' loading factor should be equal to or greater than 0.50 (Hair, Black, Babin, \& Anderson, 2010). All indicators in Job Autonomy (JA) had a satisfactory structure loading (greater than 0.50). Meanwhile, some items in job crafting (JC) and Wellbeing (WWB) must be deleted because showed unsatisfactory validity score (loading factors were under 0.50). There are seven indicators deleted in JC and six indicators in well-being.

Table 2

Loading Factors

\begin{tabular}{lccc}
\hline & Job Autonomy & Job Crafting & Well-Being \\
\hline ja1 & $(0.77)$ & & \\
ja2 & $(0.81)$ & & \\
ja3 & $(0.79)$ & & \\
ja4 & $(0.70)$ & & \\
ja5 & $(0.69)$ & & \\
ja6 & $(0.75)$ & & \\
ja7 & $(0.67)$ & & \\
ja8 & $(0.64)$ & & \\
ja9 & $(0.65)$ & $(0.68)$ & \\
jc1 & & $(0.65)$ & \\
jc2 & & $(0.60)$ & \\
jc3 & & $(0.75)$ & \\
jc5 & & $(0.68)$ & \\
jc8 & & $(0.62)$ & \\
jc11 & & $(0.56)$ & \\
jc13 & & $(0.61)$ & \\
jc14 & & $(0.60)$ & \\
jc15 & & $(0.54)$ & \\
jc16 & & $(0.52)$ & \\
jc18 & & $(0.64)$ & \\
jc19 & & $(0.75)$ & \\
jc20 & & & $(0.82)$ \\
wwb1 & & & $(0.86)$ \\
wwb2 & & & $(0.81)$ \\
wwb3 & & & $(0.79)$ \\
wwb7 & & & \\
wwb8 & & & \\
wwb9 & & & \\
& & & \\
\hline
\end{tabular}

To ensure that all items in the questionnaire met the requirement of internal consistency, Cronbach Alpha was tested. Composite reliability and the Cronbach alpha coefficients should be equal to or 
greater than 0.70 (Hair et al., 2010). The result of the reliability check is shown in Table 3 and all variables assessed in this study had a satisfactory score of composite reliability and Cronbach's Alpha ranging from $0.88-0.92$.

Table 3

Reliability Check

\begin{tabular}{lcc}
\hline Variable & Composite Reliability & Cronbach's Alpha \\
\hline Job Autonomy & 0.90 & 0.88 \\
Job Crafting & 0.90 & 0.87 \\
Well-Being & 0.92 & 0.90 \\
\hline
\end{tabular}

\section{Result and Discussion}

The means, standard deviations, and correlations between all variables are presented in Table 4 and 5 . The result shows that job autonomy is correlated positively with job crafting $\left(r=0.73^{* *}, p<0.01\right)$, but correlated negatively with well-being $\left(r=-0.21^{* *}, p<\right.$ $0.01)$. On the other hand, job crafting is negatively linked to the well-being of the employees $(r=-0.27 * *$, $p<0.01)$. The results also showed the highest mean score for job autonomy (mean $=4.49)$ and the lowest mean score for well-being $($ mean $=2.31)$.

Table 4

Means and Standard Deviation

\begin{tabular}{lcc}
\hline & Mean & SD \\
\hline 1 & - & - \\
2 & - & - \\
3 & - & - \\
4 & - & - \\
Job Autonomy & 4.49 & 0.64 \\
Job Crafting & 4.41 & 0.47 \\
Wellbeing & 2.31 & 0.76 \\
\hline
\end{tabular}

Table 5

Correlations for All Variables $(n=427)$

\begin{tabular}{|c|c|c|c|c|c|c|}
\hline 1 & 2 & 3 & 4 & JA & $\mathrm{JC}$ & WB \\
\hline 1 & $0.10^{*}$ & -0.07 & -0.02 & 0.48 & 0.06 & 0.07 \\
\hline 2 & 1 & $-0.23^{* *}$ & 0.69 & -0.08 & -0.03 & $0.11^{*}$ \\
\hline 3 & & 1 & $-0.17 * *$ & $-0.13^{* *}$ & -0.06 & 0.08 \\
\hline 4 & & & 1 & -0.00 & -0.03 & -0.02 \\
\hline JA & & & & 1 & $0.73^{* *}$ & $-0.22 * *$ \\
\hline $\mathrm{JC}$ & & & & & 1 & -0.27 \\
\hline WB & & & & & & 1 \\
\hline
\end{tabular}

\section{Hypothesis Testing}

The proposed model was estimated by conducting a path analysis through WarpPLS 7.0. The model is considered to be fit if it meets three fit model size criteria, such as Average Path Coefficient (APC), Average $R$-squared (ARS), and Average Block Variance Inflation Factor (AVIF). The result shows that the research model after data analysis using the WarpPLS program was fit indicated by general information.
Based on the results, the proposed model is accepted (Table 6) because APC is $0.53(p<0.00)$; ARS is 0.33 $(p<0.00)$, AFVIF 1.90, GoF value 0.42 (larger than $0.36)$.

Table 6

Measurement Model

\begin{tabular}{lcr}
\hline Fit Indicators & Recommendation Value & Value \\
\hline APC & & 0.53 \\
ARS & & $(p<0.00)$ \\
& & $0.33(p<0.00)$ \\
AFVIF & $\leq 3.30$ & 1.90 \\
GoF & $\geq 0.36$ (large $)$ & 0.42 \\
RSCR & $\geq 0.90$ & 1.00 \\
SSR & $\geq 0.70$ & 1.00 \\
\hline
\end{tabular}

Furthermore, the $R$-square for job crafting is 0.56 and well-being is 0.10 (Table 7). Also, we assessed the predictive validity associated with each latent variable in the model by evaluating the $Q$-squared coefficient (Table 7). If the $Q$-square value showed $>0$, we can conclude that the model has predicate relevance (vice versa). The $Q$-square coefficient in this study is 0.38 . Therefore, $38 \%$ of employees' well-being are explained by job crafting and job autonomy. $\left.Q^{2}\right)$ :

$Q$-square value estimation (predicate relevance/

$Q^{2}=1-\left(1-R_{1}^{2}\right)\left(1-R_{2}^{2}\right)$

$Q^{2}=1-\left(1-0.56^{2}\right)\left(1-0.10^{2}\right)$

$Q^{2}=1-(1-0.31)(1-0.10)$

$Q^{2}=1-(0.68)(0.90)$

$Q^{2}=1-0.62$

$Q^{2}=0.38$

Table 7

R-square

\begin{tabular}{lc}
\hline Dependent Variable & R-square \\
\hline Job Crafting & 0.56 \\
Well-Being & 0.10 \\
\hline
\end{tabular}

Table 8

Hypothesis Testing

\begin{tabular}{lccc}
\hline Hypothesis & Coef. & Prob. & Conclusion \\
\hline $\begin{array}{l}\text { Job Autonomy } \rightarrow \\
\text { Well-Being }\end{array}$ & -0.05 & $p<0.16$ & $\begin{array}{c}\text { Hypothesis } \\
\text { rejected }\end{array}$ \\
$\begin{array}{l}\text { Job Autonomy } \rightarrow \text { Job } \\
\quad 0.75\end{array}$ & $p<0.00$ & $\begin{array}{c}\text { Hypothesis } \\
\text { accepted }\end{array}$ \\
$\begin{array}{l}\text { Crafting } \\
\text { Job Crafting } \rightarrow \text { Well- }\end{array}$ & 0.28 & $p<0.00$ & $\begin{array}{c}\text { Hypothesis } \\
\text { accepted }\end{array}$ \\
$\begin{array}{l}\text { Being } \\
\text { Job Autonomy } \rightarrow \text { Job }\end{array}$ & & & $\begin{array}{c}\text { Hypothesis } \\
\text { accepted }\end{array}$ \\
$\quad \begin{array}{l}\text { Crafting } \rightarrow \text { Well- } \\
\text { Being }\end{array}$ & -0.20 & $p<0.00$ & \\
\hline
\end{tabular}

Based on the result shown in Table 8, it reveals an interesting point. The direct relationship between job autonomy and employee's well-being $(\beta=-0.05 ; p<$ 0.16 ) is not significant; hence this result does not 
support the hypothesis. The study also finds a significant association between job autonomy and job crafting $(\beta=0.75 ; p<0.00)$. Table 8 shows that job crafting is positively and significantly associated with well-being $(\beta=0.28 ; p<0.00)$. In the association of work autonomy and well-being, the mediating role of job creation is supported in this study $(\beta=-0.20 ; p<$ $0.00)$. Remarkably, the result reveals a negative direction in the association of job autonomy and wellbeing $(\beta=-0.20)$. Unlike prior research that has largely emphasized the positive direction, this result gives a different view of these variables association.

\section{Discussion}

The high attention to employees' well-being has become prominent since COVID-19 hit the world. Workplace stress reaches a peak level because people have to adapt to a new routine and ways of work and life. COVID-19 pandemic has changed employees' expectancy of a workplace. Employees are looking for higher flexibility to experience better well-being. Thus, the purpose of the current study is to examine the relationship between job autonomy and well-being. More specifically, the purpose is to address the mediating effects of job crafting on the relationship between job autonomy and well-being. As a result, this study shines a light on current insight into job design and factors that promote well-being.

Hypothesis 1 states that a curvilinear relationship would exist between job autonomy and well-being. This means that when employees experienced a high job autonomy, their well-being would increase (Yang $\&$ Zhao, 2018). The result of the analysis does not support a positive relationship. The direct relationship between job autonomy and employee's well-being is not significant. This result challenges the previous finding that have a positive effect of job autonomy on well-being. This study is conducted during the pandemic when employees have to work from home without proper monitoring policy. Accordingly, employees experience an excessive degree of job flexibility and it gives them more work pressure, aggravates job burnout, creates an opportunity for deceitful behavior, and reduces their subjective happiness (Zhou, 2020; Kubicek, Paskvan, \& Bunner, 2017). Crawford and LePine (2013) stated that "too-much-of-a-good-thing" might make the loss larger compared to the benefit expected (Figure 2).

Job autonomy is hypothesized to be related to job crafting in hypothesis 2 . Theoretically, job autonomy provides the precondition that enables more self-determined and discretionary behaviors in an organization, such as job crafting. Job crafting is a voluntary behavior aimed at finding significance and personal development by asking colleagues for advice, asking for more assignments and challenges, reducing emotional and mental requirements, changing physical workspace. The result reveals that job autonomy significantly affects job crafting $(\beta=0.75 ; p<0.00)$. This supports previous findings (e.g. Debus et al., 2019; Vanbelle, Van den Broeck, \& De Witte, 2017; Guan \& Frenkel, 2018) that explains that when employees have a satisfactory degree of freedom and the job demands are high, employees will tend to modify aspects of the task according to their skills, and preference. They are even able to increase challenge when the job is under stimulating. Flexibility allows them to reduce job demands that delivered pressure emotionally and physically.

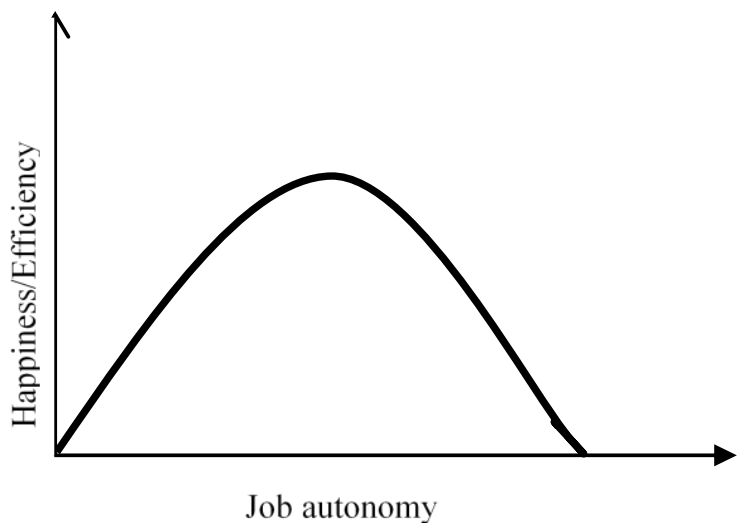

Figure 2. Inverted U shape curve

Source: Zhou, 2020.

The direct effect of job crafting and well-being is also supported in this study (hypothesis 3). By engaging in job crafting, employees will basically reshape their job to become more closely aligned with their skills, preferences, and motivation for work. This process affects the nature of the job itself, including the demands experienced, resources, and meaning of the work. This result is parallel with previous studies. Tims et al. $(2012 ; 2013)$ had found that job crafting enabled individuals to strike an equilibrium between the demands and also the personal resources they needed to perform that helped against burnout, exhaustion, and increases engagement.

Hypothesis 4 states that job crafting would mediate the relationship between job autonomy and well-being. Perceived autonomy at the workplace would lead to job crafting behavior, which in turn would be associated with higher subjective well-being. The result of this study supports hypothesis 4 , which is consistent with what was found by Slemp et al. (2015), 
and Saragih et al. (2020). These result indicates that during the pandemic, employees who enjoy flexibility (in choosing time, methods, and place) to accomplish their works are prone to redefine their job to fit their needs and make their job more satisfying, meaningful, and leading to better well-being (Demerouti \& Bakker, 2014).

\section{Conclusions and Implications}

Based on the above discussion, this study concludes that job autonomy also harms employees' well-being. In other words, the high levels of flexibility at the workplace contribute to detrimental effects on employees' well-being. Job autonomy creates a curvilinear function, well-being increases from low to medium levels, but it decreases when employees experience an excessive level of freedom. Employees feel more insecure and they are not sure about what they need to do. While job autonomy leads to a voluntary behavior, called job crafting, job autonomy allows employees to take control over how they execute their tasks. Therefore, employees tend to alter the nature of their job to align the demand and resources with their personal preferences. This finding gives practical contribution for organizations and supervisors to provide an optimal level of independence and flexibility at the workplace. In addition, an evaluation standard should be explained beforehand. Therefore, the employees know how they will evaluate and finish their work.

This study agrees that job crafting mediates job autonomy and well-being. Having the flexibility to work remotely during the pandemic increases employees' perception of making more independent and self-directed decisions to accomplish their tasks (Gajendran et al., 2014). This relates to higher engagement and subjective well-being. This result also indicates that managers should focus on results delivery because it goes hand-in-hand with job autonomy. When managers give an employee flexibility during remote work, it is important to assess whether they are delivering outstanding results.

Evident from the survey conducted during the pandemic by the Mental Health Association of Hong Kong (Vyas \& Butakhieo, 2021), it is found that during WFH employees experience more stress, fear regarding job security, feel anxious, lonely, bored, and exhausted. Therefore, organizations need to provide supports (e.g. trust, clear direction, communication, proper monitoring, and flexibility about specific work arrangements).

Our present study has its limitations that acknowledge points to future studies. First, this study only focused on job autonomy as an independent variable. Future research might help to establish the complex path involving more independent variables (e.g. social support, workload). Second, in this study analysis, job crafting was treated as uni-dimensional variable. Based on the initial study by Tims et al. (2012), job crafting consists of four dimensions. Future research should treat each job crafting's dimension as an individual dimension in the data analysis.

\section{References}

Breaugh, J. A. (1999). Further investigation of the work autonomy scales: Two studies. Journal of Business and Psychology, 13(3), 357-373. https://doi.org/10.1177/001872678704000604

Chang, P. C., Rui, H. \& Wu, T. (2021). Job autonomy and career commitment: A moderated mediation model of job crafting and sense of calling. SAGE Open, 11(1), 1-11. https:// doi.org/10.1177/21582440211004167

Crawford, E. R., \& LePine, J. A. (2014). A configural theory of team processes: Accounting for the structure of taskwork and teamwork. Academy of Management Review, 38(1), 32-48. https://doi.org/ 10.5465/amr.2011.0206

Crawford, E. R., LePine, J. A., \& Rich, B. L. (2010). Linking job demands and resources to employee engagement and burnout: A theoretical extension and meta-analytic test. The Journal of Applied Psychology, 95(5), 834-848. https://doi.org/ 10.1037/a0019364

Debus, M., Gross, C., \& Kleinmann, M. (2020). The power of doing: How job crafting transmits the beneficial impact of autonomy among overqualified employees. Journal of Business and Psychology, 35(3), 317-331. https://doi.org/10.1007/ s10869-019-09625-y

Deci, E. L., \& Ryan, R., M. (2008). Self-determination theory: A macro theory of human motivation, development, and health. Canadian Psychology, 49(3), 182-185 https://doi.org/10.1037/A0012801

Demerouti, E., \& Bakker, A. B. (2014). Job crafting. In M. C. W. Peeters, J. De Jonge, \& T. W. Taris (Eds.), An introduction to contemporary work psychology (pp. 414-437). Wiley Blackwell.

Franken, E., Bentley, T., Shafaei, A., Farr-Wharton, B., Onnis, L., \& Omari, M. (2021). Forced flexibility and remote working: Opportunities and challenges in the new normal. Journal of Management \& Organization, 1-19. https://doi.org/10.1017/jmo. 2021.40

Gajendran, S. R., Harrison, A. D., \& Delaney-Klinger, K. (2014). Are telecommuters remotely good citizens? Unpacking telecommuting's effects on 
performance via i-deals and job resources. Personnel Psychology, 68(2), 353-393. https://doi.org/ 10.1111/peps. 12082

Guan, X., \& Frenkel, S. (2018). How HR practice, work engagement and job crafting influence employee performance. Chinese Management Studies, 12(3), 591-607. https://doi.org/10.1108/ CMS-11-2017-0328

Hackman, J. R., \& Oldham, G. R. (1976). Motivation through the design of work: Test of a theory. Organizational Behavior \& Human Performance, 16(2), 250-279. https://doi.org/10.1016/ 0030-5073(76)90016-7

Hair, J. F., Black, W. C., Babin, B. J., \& Anderson, R. E. (2010). Multivariate data analysis. $7^{\text {th }}$ Edition. New York, NY: Pearson.

Hakanen, J. J., \& Roodt, G. (2010). Using the job demands-resources model to predict engagement: Analysing a conceptual model. In A. B. Bakker, \& M. P. Leiter (Eds.). Work engagement: A Handbook of essential theory and research, pp. 85-101. New York, NY: Psychology Press.

International Labour Organization. (2020). Teleworking during the COVID-19 pandemic and beyond: A practical guide. Retrieved from https://www.ilo.org/wcmsp5/group s/pub lic/--ed_protect/---protrav/---travail/doc uments/instructionalmaterial/wcms_751232.pdf

Kim, H., Im, J., Qu, H. N., \& Koong, J. N. (2018). Antecedents and consequences of job crafting: An organizational level approach. International Journal of Contemporary Hospitality Management, 33(3), 1863-1878. https://doi.org/10.1108/ IJCHM-01-2017-0040

Kristof-Brown, A. L., Zimmerman, R. D., \& Johnson, E. C. (2005). Consequences of individual's fit at work: A meta-analysis of person-job, personorganization, person-group, and person-supervisor fit. Personnel Psychology, 58(2), 281-342. https://doi.org/10.1111/j.17446570.2005.00672.x

Kubicek, B., Paskvan, M., \& Bunner, J. (2017). The bright and dark sides of job autonomy. In $\mathrm{C}$. Korunka, \& B. Kubicek (Eds.), Job demands in a changing world of work (pp. 45-63). Springer, Cham. https://doi.org/10.1007/978-3-319-54678 $-04$

Li, J., Han, X., Qi, J., \& He, X. (2020). Managing one's career: The joint effects of job autonomy, supervisor support, and calling. Journal of Career Development, 1-14. https://doi.org/10.1177/089 4845320906464
Nielsen, K., \& Abildgaard, J. (2012). The development and validation of a job crafting measure for use with blue-collar workers. Work \& Stress, 26(4), 365-384, https://doi.org/10.1016/j.jvb.2011.05.009

Palumbo, R. (2020). Let me go to the office! An investigation into the side effects of working from home on work-life balance. International Journal of Public Sector Management, 33(6-7). https://doi.org/10.1108/IJPSM-06-2\%20020, 0150

Park, R., \& Jang, S. (2015). Mediating role of perceived supervisor support in the relationship between job autonomy and mental health: Moderating role of value-means fit. The International Journal of Human Resource Management, 28(5), 703-723. https://doi.org/10 $.1080 / 09585192.2015 .1109536$

Park, R., \& Searcy, D. (2012). Job autonomy as a predictor of mental well-being: The moderating role of quality-competitive environment. Journal of Business and Psychology, 27(3), 305-316. https://doi.org/10.1007/s10869-01 1-9244-3

Petrou, P., Demerouti, E., Peeters, C. W., Schaufeli, B. W., \& Hetland, J. (2012). Crafting a job on a daily basis: Contextual correlates and the link to work engagement. Journal of Organizational Behavior, 33(8), 1120-1141. https://doi.org/10.1002/ job. 1783

Petrou, P., Demerouti, E., \& Schaufeli, W. B. (2018). Crafting the change: The role of employee job crafting behaviors for successful organizational change. Journal of Management, 44(5), 17661792. https://doi.org/10.1177/0149206315624961

Saragih, S., Margaretha, M., \& Situmorang, A. (2020). Analyzing antecedents and consequence of job crafting. International Journal of Management, Economics and Social Sciences, 9(2), 76-89. https://doi.org/10.32327/IJ MESS/9.2.2020.5

Sato, A. (2013). Teleworking and changing workplaces. Japan Labor Review, 10(3), 56-69. http://www.jil.go.jp/english/JLR/documents/201 3/JLR39_sato.pdf

Sekiguchi, T., Li, J., \& Hosomi, M. (2017). Predicting job crafting from the socially embedded perspective: The interactive effect of job autonomy, social skill, and employee status. The Journal of Applied Behavioral Science, 53(4), 470-497. https://doi.org/10.1177/0021 886317727459

Simone, S. (2014). Conceptualizing wellbeing in the workplace. International Journal of Business and Social Science, 5(12), 118-122.

Singh, V. L., \& Singh, M. (2018). A burnout model of job crafting: Multiple mediator effects on job performance. IIMB Management Review, 30(4), 
305-315. https://doi.org/10.1016/j.iimb.2018.05. 001.

Slemp, G., Kern, M., \& Vella-Brodrick D. (2015). Workplace well-being: The role of job crafting and autonomy support. Psychology of WellBeing, 5(7), 16-17. https://doi.org/10.1186/s136 12-015-0034-y.

Tims, M., Bakker, A. B., \& Arnold, B. (2010). Job crafting: Towards a new model of individual job redesign. SA Journal of Industrial Psychology, 36(2), 1-9. https://doi.org/10.4102/sajip.v36i2.841

Tims M., Bakker, A. B., \& Derks, D. (2012). Development and validation of the job crafting scale. Journal of Vocational Behavior, 80(1), 173-186. https://doi.org/10.1016/J.JVB.201 1.05.009.

(2013). The impact of job crafting on job demands, job demands, job resources, and wellbeing. Journal of Occupational Health Psychology, 18(2), 230-240. http://doi.org/10.1037/ a0032141.

Vanbelle, E., Van den Broeck, A., \& De Witte, H. (2017). Job crafting: Autonomy and workload as antecedents and the willingness to continue working until retirement age as a positive outcome. Psihologia Resurselor Umane Revista Asociaţiei de Psihologie Indusstrială şi Organizaţională, 15(1), 25-41. https://doi.org/10.24837/ pru.2017.1.3.
Van-Wingerden, J., Bakker, A., \& Derks, D. (2017). Fostering employee well-being via a job crafting intervention. Journal of Vocational Behavior, 100, 164-174. https://doi.org/10.1016/j.jvb.2017. 03.008

Vyas, L., \& utakhieo, N. (2021). The impact of working from home during COVID-19 on work and life domains: An exploratory study on Hong Kong. Policy Design and Practice, 4(1), 59-76. https://doi.org/10.1080/2574129\%202.2020.186 3560.

Warr, P. (1990). The measurement of well-being and other aspects of mental health. Journal of Occupational Psychology, 63, 193-210. https://doi.org/ 10.1111/j.2044-8325.1990.tb 00521.x.

Wrzesniewski, A., \& Dutton, J. (2001). Crafting a job: Revisioning employees as active crafters of their work. Academy of Management Review, 26(2), 179-201. https://doi.org/10.230 7/259118.

Yang, F., \& Zhao, Y. (2018). The effect of job autonomy on psychological well-being: The mediating role of personal initiative. Open Journal of Social Sciences, 6(11), 234-248. https://doi.org/10.4236/jss.2018.611017.

Zhou, E. (2020). The "too-much-of-a-good-thing" effect of job autonomy and its explanation mechanism. Psychology, 11(2), 299-313. https://doi.org/10.4236/psych.2020.112019. 